\section{$\underset{\substack{\text { hommes } \\ \text { \& migrations }}}{ }$}

\section{Hommes \& migrations}

Revue française de référence sur les dynamiques

migratoires

1307 | 2014

L'Afrique qualifiée dans la mondialisation

\title{
Passé et présent d'une double appartenance
}

\section{Akil Marceau}

\section{OpenEdition \\ Journals}

\section{Édition électronique}

URL : http://journals.openedition.org/hommesmigrations/2898

DOI : 10.4000/hommesmigrations.2898

ISSN : 2262-3353

\section{Éditeur}

Musée national de l'histoire de l'immigration

\section{Édition imprimée}

Date de publication : 1 juillet 2014

Pagination : 136-139

ISBN : 978-2-919040-28-5

ISSN : $1142-852 X$

\section{Référence électronique}

Akil Marceau, «Passé et présent d'une double appartenance », Hommes \& migrations [En ligne], 1307 | 2014, mis en ligne le 15 janvier 2015, consulté le 22 septembre 2020. URL : http:// journals.openedition.org/hommesmigrations/2898; DOl : https://doi.org/10.4000/ hommesmigrations.2898 


\section{REPÉRAGE}

\section{PASSÉ ET PRÉSENT D'UNE DOUBLE APPARTENANCE}

AKIL MARCEAU, directeur de la Représentation du Gouvernement Régional du Kurdistan-Irak en France.

"Kurdes d'Auvergne, Français d'ailleurs..." est le titre choisi par la Représentation du Kurdistan-Irak en France pour présenter une exposition mémorielle et itinérante, qui met en évidence le parcours d'une dizaine de Français de la France d'aujourd'hui. Des portraits de personnages représentant notamment l'ordre (gendarme, policier), le droit (avocate) ou l'État (agent du fisc). Ils ont, entre autres choses, deux points communs : ils sont citoyens français et ont un passé kurde. Être et avoir : fiers d'être français et heureux d'avoir des origines kurdes. Aujourd'hui, ils jettent des passerelles, s'investissent dans des projets prometteurs entre, d'un côté, leur pays adoptif et de naissance, et de l'autre, le pays de la première génération. Dans le pays d'origine, le Kurdistan d'Irak, plusieurs rues, places publiques et écoles portent le nom de personnages politiques français, comme l'école Danielle-Mitterrand, la place François-Mitterrand, signes de reconnaissance envers la France qui leur est venue en aide pendant les années noires de la répression et du génocide.

Cette exposition met en avant des citoyens français d'origine kurde et des binationaux, leur intégration et leur contribution au pays adoptif avec une chronologie illustrée. II n'est pas sans intérêt de faire un bref rappel historique de la présence kurde dans l'Hexagone, tout en mettant en exergue l'histoire de leur pays d'origine.

\section{Une double appartenance déjà ancienne}

Dans la presse de l'Hexagone, les premiers articles relatant des événements au Kurdistan et évoquant ses habitants parurent au début du XXe siècle. À cette époque en France, seuls quelques initiés, notamment dans le milieu politique et diplomatique, étaient familiers de la question kurde. Le sort de l'Empire ottoman ("I'homme malade" de l'Europe) et des territoires jusque-là sous sa domination, dont le Kurdistan, fut scellé par les négociations de Versailles, puis par le traité de Sèvres, à la fin de la Grande Guerre. La délégation kurde aux négociations de paix, conduite par Cherif Pacha, ou le "Beau Pacha", ou encore le "Pacha Stambouliote", selon la presse francophone de l'époque, réussit à inscrire à l'ordre du jour des négociations l'autodétermination du peuple kurde, à l'instar des autres peuples sous le joug ottoman. Les articles 62 à 64 du traité de Sèvres portent spécifiquement sur la question kurde. La partie du Kurdistan sous l'Empire perse n'était cependant pas concernée par ces accords. Le général Cherif Pacha, francophone et francophile, qui avait fait ses études au lycée français de Galatasaray à Istanbul, avant d'intégrer Saint-Cyr en France, où il fut ensuite diplomate pendant 
la majorité des peuples, sans pour autant magnifier leur statut sous les empires, jouissaient à divers degrés du droit à leur identité : "le soi collectif" et l'appartenance à un groupe. Le Kurde n'était pas encore désigné comme un "Turc montagnard" ou comme un Irakien de "notre cher Nord".

\section{Black-out sur la question kurde}

On n'entendit plus parler des Kurdes dans l'Hexagone jusqu'aux années 1980. Sous l'empire, on pouvait être sujet impérial et avoir des origines diverses. Les États-nations autoritaires, bâtis sur ses décombres, imposent, eux, l'Être ou le néant : être turc, irakien, syrien, iranien, ou rien. Silence total à l'intérieur des frontières enfermant la plus grande nation dans le monde sans État. Black-out

Exposition itinérante Kurdes d'Auvergne, Français d'Ailleurs (c) KRG

quelques années, prônait une alliance de la Turquie avec la France contre l'Allemagne. La presse parisienne couvrit la tentative d'assassinat perpétrée contre lui à son domicile parisien, rue de la Pompe, le 14 janvier 1914. II accusa les nationalistes Jeunes-Turcs pro-allemands. Ses origines kurdes furent aussi évoquées comme un motif par la presse.

Que ce soit sous l'Empire ottoman ou l'Empire perse, les Kurdes avaient toujours, de gré et souvent de force, une double appartenance : une gestion autonome au sein de leurs principautés et une allégeance aux sultans et aux shahs. Ces derniers gardaient la main sur la sécurité des frontières et les affaires extérieures. Cette double appartenance et cette dualité d'allégeance étaient, jusqu'à la veille de la Première Guerre mondiale, sous les empires et par la suite sous les mandats français et britannique, le sort de la plupart des peuples constitués aujourd'hui en Étatsnations. Avant de passer à l'âge des États-nations, total et interdiction de toute libre expression dans les nouveaux États-nations : "l'autoritarisme oriental" est à l'œuvre.

Quelques rares articles néanmoins, dans Le Figaro, L'Écho de Paris ou le journal Liberté, couvrirent les performances de la danseuse de ballet, Leyla Bedirkhan, dans les années 1930. Descendante de la dynastie kurde des Bedirkhan du côté de son père, celle-ci avait élu domicile à Paris. De mère suisse et mariée à un artiste polonais, son appartenance kurde lui importait. Dans une interview, elle insistait sur cette appartenance en déclarant: "Je ne suis pas persane, je suis kurde. Mon grand-père était le prince du Kurdistan. Pays aux confins de la Perse, de la Turquie et de la Syrie." Des publications et livres en langue kurde purent néanmoins être publiés par la diaspora grâce à des intellectuels kurdes en exil. L'apport de la diaspora ne cessa de grandir et d'influencer les courants d'idées au Kurdistan. Le premier journal portant le nom "Kurdistan" parut au Caire, édité par un prince de la dynastie Bedirkhan. Toujours au sein de cette même dynastie, qui s'est illustrée 
Cherif Pacha $₫$ ARCHIVES

dans les œuvres produites par l'intelligentsia de l'exil et de la diaspora, deux autres princes, les frères Djeladet et Kamuran Badirkhan, sont à l'origine du renouveau de la littérature kurde et de plusieurs journaux et magazines bilingues franco-kurdes, parus sous le mandat français, sur la Syrie et le Liban. Exilé à Paris, l'émir Kamuran Bedirkhan enseigna pendant les années 19501960 la langue kurde à l'Institut national des langues et civilisations orientales (Inalco), à Paris.

Dans les États du Moyen-Orient où vivent les Kurdes, les idéologies mises en place par les nouveaux dirigeants arrivés au pouvoir après la chute de l'Empire ottoman et la fin des mandats britannique et français cherchaient à éradiquer tout obstacle à la construction étatique. En Turquie, l'utilisation du mot "Kurde" devient un délit. En Syrie, une partie des Kurdes sont déchus de leur nationalité. En Irak, le parti Baas mettra en place la politique de la terre brûlée, des plans d'extermination et l'usage d'armes chimiques. Ces politiques discriminatoires à l'égard des Kurdes poussèrent nombre d'entre eux à l'exil vers les pays européens. Pendant les Trente Glorieuses, quand la France manquait de main-d'œuvre, de nombreux Kurdes, en particulier de Turquie, sont arrivés en France. Les coups d'État militaires successifs en Turquie, en 1970 et 1980, poussèrent à l'exil de nombreux autres Kurdes, dont le cinéaste Yilmaz Güney, Palme d'or au Festival de Cannes en 1982 pour son film Yol.

\section{Quand les Kurdes deviennent auvergnats}

C'est vers la fin de la guerre Iran-Irak que le régime de Saddam Hussein met en place un plan de génocide contre la population kurde sous le nom de code Anfal. C'est la première fois depuis la Première Guerre mondiale que des armes chimiques sont utilisées de façon aussi massive contre des populations civiles. Dans la ville kurde d'Halabja, le 16 mars 1988, plus de 5000 Kurdes sont asphyxiés. L'Anfal s'est déroulé sur deux ans, conduit par le cousin de l'ancien dictateur irakien, le général connu désormais 
de France en Turquie au gendarme de BourgLastic, tout le monde se mobilise. Il faut sélectionner les familles dans le camp de Mardin, en Turquie, négocier avec les autorités turques en guerre avec leurs propres Kurdes, trouver des municipalités en France qui voudront bien les accueillir, leur faire des papiers, scolariser les enfants, trouver des stages aux adultes. II a fallu inventer des méthodes de travail, tordre les règlements, répondre à l'urgence. Pour donner de la visibilité à ce moment fort, à des actes de générosité et de solidarité citoyenne et républicaine, à cette page de l'histoire contemporaine kurde, mais aussi pour commémorer le $25^{\mathrm{e}}$ anniversaire du génocide kurde, la Représentation du gouvernement du Kurdistan-Irak a lancé cette exposition, réunissant des documents d'archives, des éléments audiovisuels, des photos

Exposition itinérante Kurdes d'Auvergne, Français d'Ailleurs (c) KRG

sous le nom d'“Ali le Chimique”. Des actes génocidaires, plus de 4 ooo villages rasés au bulldozer, des sources d'eau bétonnées, des nappes phréatiques et des terres arables contaminées, dont les conséquences se font sentir encore aujourd'hui. Des séquelles physiques et psychiques marquent et marqueront encore longtemps les habitants et l'environnement.

En août 1989, 337 Kurdes irakiens, pour moitié des enfants, arrivent au camp militaire de BourgLastic en Auvergne, dans le cadre d'une opération humanitaire menée par Danielle Mitterrand. D’autres réfugiés kurdes suivront les mois suivants. Ce sont des survivants. Ils ont fui l'Anfal. Avant d'arriver en France, ces Kurdes ont transité dans des camps de fortune sur le territoire turc, où ils n'étaient, de toute façon, pas les bienvenus. Cette opération humanitaire reste aujourd'hui une rencontre exemplaire entre la République et un peuple menacé d'anéantissement. À tous les échelons de l'administration, de l'ambassadeur anciennes et des portraits de jeunes issus de la deuxième génération.

Présentée à la mairie du $X X^{e}$ arrondissement de Paris en septembre 2013, l'exposition Kurdes d'Auvergne, Français d'ailleurs a été programmée à nouveau du 24 juin au 5 juillet 2014 à l'hôtel SaintSimon de la mairie d'Angoulême. Elle bivouaquera par la suite à la mairie de Clermont-Ferrand et une commémoration de l'arrivée des réfugiés à Bourg-Lastic y sera célébrée entre "Auvergnats". Au travers de la dizaine de portraits issus de ce groupe, nous découvrons des parcours de vie qui racontent l'intégration dans le pays d'accueil. À Bourg-Lastic, Mainsat, Vic-le-Comte, Piriac-surMer ou Auzon, bien au-delà du destin des familles accueillies, I'histoire des "Kurdes d'Auvergne" contribue à construire l'avenir de leur nouveau pays. Cette exposition raconte une rencontre exemplaire entre ces réfugiés et la République, en ce mois d'août 1989, au moment où la France tout entière fêtait le bicentenaire de la Révolution et de la Déclaration des droits de l'homme et du citoyen. 